\title{
28 Research Square \\ Characterization of chemotaxis and motility response towards fructose in Escherichia coli
}

Fanghai Liu

School of Food and Biological Engineering, Hefei University of Technology

Fangbin Wang ( $\nabla$ fbwang@hfut.edu.cn )

School of Food and Biological Engineering, Hefei University of Technology

Jian Liu

School of Food and Biological Engineering, Hefei University of Technology

\section{Research article}

Keywords: Escherichia coli, fructose, chemotaxis, motility

Posted Date: January 24th, 2020

DOI: https://doi.org/10.21203/rs.2.21816/v1

License: (1) This work is licensed under a Creative Commons Attribution 4.0 International License. Read Full License

Version of Record: A version of this preprint was published at Biochemical and Biophysical Research Communications on June 1st, 2020. See the published version at https://doi.org/10.1016/j.bbrc.2020.04.087. 


\section{Abstract}

\section{Background}

Peritrichously flagellated bacteria such as Escherichia coli perform chemotaxis by a biased random walk toward various chemicals, which was driven by the bacterial flagellar motor. The chemotaxis system is a perfect robust system which can adapt to its pre-stimulus level after the stimulus. Fructose, a typical monosaccharide that can attract Escherichia coli. Previous studies have shown Escherichia coli to be chemotactic to both amino acids and simple sugars. However, little is known about the chemotaxis and motility response of Escherichia coli towards fructose.

\section{Results}

In this study, we characterized the chemotaxis behavior of Escherichia coli to different concentrations of fructose from $0 \mathrm{mM}$ to $50 \mathrm{mM}$ by using microfluidics and bead assay. We observed the wild-type cells responded to the stimulus of fructose, which suggested fructose is an attractant to Escherichia coli, while the cells defective in chemotaxis could not sense the stimulus of fructose. Fructose affects the motor behavior of wild-type cells and reduces the CCW motor speeds significantly compared to CW motor speeds, contrast to that fructose cannot affect the motor speeds of cells defective in chemotaxis. The CW biases of wild-type cells increased with the addition of fructose. And the fructose promotes bacterial aggregation on surface by lowering the bacteria motor speed.

\section{Conclusions}

We found that fructose is an attractant to Escherichia coli, with the wild-type cells showed stronger response to higher concentration of fructose, while cells lacking chemoreceptors and CheY cannot sense or respond to fructose. The motility of wild-type cells was reduced in various concentrations of fructose, which helped the aggregation of cells near the surface, in contrast with the result that the fructose showed no effect on the motility of the cells defective in chemotaxis. Similar phenomena are expected to be found in the effect of other monosaccharides to Escherichia coli.

\section{Background}

Bacteria such as Escherichia coli can sense and respond to the gradients of attractants or repellents in the circumstance via the chemotaxis system, with receptor clusters process the input signal, while the flagellar motor generate output to drive the bacteria moves in a random walk pattern, alternating between runs and tumbles (1-3). The bacterium runs when all of the flagellar motors on the cell rotate in a counterclockwise (CCW) direction, reversely tumbles when one or more motors rotate in a clockwise (CW) direction (4). The activity of a histidine kinase CheA is modulated by binding of the chemicals to receptors, which changes the level of phosphorylation of $\mathrm{CheY}$, the response regulator of the chemotaxis signaling pathway. Phosphorylated $\mathrm{CheY}(\mathrm{CheY}-\mathrm{P}$ ) binds to the component of flagellar motor-switch complex, FliM, thereby increasing the probability of the flagellar motor rotating in $\mathrm{CW}$ direction (increasing 
the CW bias) (5). The chemotaxis system is a perfect robust system which can adapt to its pre-stimulus level after the stimulus (6). As the system output, the motor rotation directional bias was used in measuring the adaptation time.

The bacterium of E. coli is propelled by the flagellar motor, which is pumped by the proton motive force (PMF) (7). PMF drives the flow of protons through the inner trans-membrane channels of the stator complex, composed by the protein MotA and MotB (8). The stators interact with the rotor complex which consists of FliG, FliM and FliN to generate the motor torque through electrostatic interactions (9). The motor was shown to be a dynamic structure with stators binding on and off it. The motor switches

between CCW direction and CW direction, which determines the run-tumble mode of the bacteria (10). The motility of the bacteria characterized by the bacterial swimming speed depends strongly on the rotational speed of the flagellar motor.

Previous studies have shown E. coli to be chemotactic to both amino acids and simple sugars (11-12). Evidence presented by Julius Alder et al. (11) suggests that the cells of E. coli were attracted to simple sugars such as glucose, galactose, ribose, mannose, arabinose and fructose. However, few studies have investigated the effect of fructose on the chemotactic behavior of E. coli in a wide range of fructose concentrations, along with the motility response of E. coli towards fructose. In this study, we explored the chemotaxis and the motility of E. coli towards a wide range of fructose concentrations from zero to $50 \mathrm{mM}$. To understand the behavioral consequences of fructose directly, we measured the chemotactic response curve of cells to different concentrations of fructose by using microfluidics and bead assay, we also compared the steady-state distributions of bacteria swimming between two parallel surfaces for wild-type cells and cells defect in chemotaxis to the wide range of fructose concentrations from zero to $50 \mathrm{mM}$.

\section{Results}

Fructose is an attractant to $\mathrm{E}$. coli

We used a wild-type strain JY26 ( $\triangle \mathrm{fliC})$, which is a derivative of E. coli K12 strain RP437, for this experiment. The plasmid pKAF131 which constitutively expresses the sticky filament FliC ${ }^{\text {st }}$ was transformed into JY26 in this study. We studied its response to a stepwise stimulus of fructose under various concentrations $(0,0.1 \mathrm{mM}, 1 \mathrm{mM}, 10 \mathrm{mM}, 20 \mathrm{mM}, 50 \mathrm{mM})$. The kinetics of the flagellar motor was monitored with a bead assay, with the motor CW bias (the probability of the flagellar motor rotating clockwise) was used as the indicator of the chemotactic output (16). The motor CW bias was stable without the addition of fructose as shown in Fig. 1A. The value of the motor CW bias was around 0.15 , which is in consistent with the previous result. In contrast, the motor $\mathrm{CW}$ bias abruptly dropped after the stepwise stimulus of fructose at time $180 \mathrm{~s}$, then it slowly recovered to its pre-stimulus level (Fig. 1B-F). After the removal of the stepwise stimulus of fructose at time $660 \mathrm{~s}$, the motor CW bias increased rapidly to the peak and decrease to its pre-stimulus level (Fig. 1B-F). The results above suggested fructose is an attractant to E. coli. 
Our measurements showed that fructose is not only an attractant to E. coli, but also influences the response degree and recovery time of E. coli under various concentrations. As shown in Fig. 1B-D, the motor $\mathrm{CW}$ bias added with the stepwise stimulus of fructose $(0.1 \mathrm{mM}, 1 \mathrm{mM}, 10 \mathrm{mM})$ dropped to the level above 0 , while the $\mathrm{CW}$ bias dropped to 0 after the addition of the stepwise stimulus of fructose $(20 \mathrm{mM}$, $50 \mathrm{mM}$ ) in Fig. 1E-F. Thus, E. coli showed a stronger response to the higher concentration of fructose. The recovery time was defined as the duration time from the time adding the stimulus to the time $\mathrm{CW}$ bias returned back to its pre-stimulus level. The recovery time were $59 \pm 10.2 \mathrm{~s}, 113 \pm 9.1 \mathrm{~s}, 171 \pm 13.3 \mathrm{~s}$, $105 \pm 11.1 \mathrm{~s}, 77 \pm 5.8 \mathrm{~s}$, corresponding to the concentration of fructose $0.1 \mathrm{mM}, 1 \mathrm{mM}, 10 \mathrm{mM}, 20 \mathrm{mM}$, $50 \mathrm{mM}$, respectively, in which, cells in medium of $0.1 \mathrm{mM}$ and $50 \mathrm{mM}$ fructose recovered faster than cells in medium of $1 \mathrm{mM}, 10 \mathrm{mM}, 20 \mathrm{mM}$. Interestingly, we also observed the overshoot phenomenon (14) which has been observed before in the step response of $\mathrm{E}$. coli to $50 \mathrm{mM}$ fructose.

CheY is essential for the chemotaxis of E. coli to fructose

To test the effect of CheY on the chemotaxis of E. coli to fructose, we measured the CW bias of the strain JY27 ( $\Delta$ fliC $\Delta$ CheY) which is derived from JY26 and transformed with the plasmid pKAF131 to express

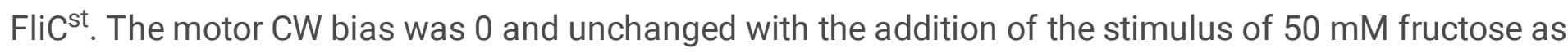
shown in Fig. 2A, which is distinct from the result of wild-type strain JY26. The motor CW bias was determined by the coupling of phosphorylated CheY (CheY-P) and motor switch complex, the more CheY$\mathrm{P}$ binds to motor switch complex, the higher motor $\mathrm{CW}$ bias. Since CheY was deleted in JY27, there were no CheY molecules could be phosphorylated in the cells of JY27, thus the motor CW bias was 0 . In addition, the cells showed no response to fructose for the reason no CheY-P could be dephosphorylated in the cells of JY27.

\section{E. coli needs chemoreceptors to sense fructose}

The strain HCB429 ( $\Delta$ (tar-tap) $\Delta \operatorname{tsr} \Delta \operatorname{trg})$ and HCB316( $\Delta$ (tar-tap) and $\Delta$ tsr), both of which derived from $E$. coli RP437, were used in the experiment. The plasmid pKAF131 which constitutively expresses the sticky filament FliC ${ }^{\text {st }}$ was transformed into HCB429, and the plasmid pFD313 which constitutively expresses sticky filament Flic ${ }^{\text {st }}$ was transformed into HCB316 in this study. Considering the cells of wild type strain response significantly to the stimulus of fructose at the concentration of $50 \mathrm{mM}$, we used it as the stimulus to the cells of HCB429. The motor CW bias of HCB429 cells was unchanged with the addition of stimulus and removal of stimulus, as shown in Fig. 2C. To further verify it, we performed the experiment with the stimulus of fructose at the concentration of $1 \mathrm{mM}$, the result of which shown in Fig. 2B was in consistent with the result shown in Fig. 2C. The number of $\mathrm{CW}$ bias was 0 all the time remarkably.

The stimulus of fructose $(1 \mathrm{mM}, 10 \mathrm{mM}, 50 \mathrm{mM})$ were used in the chemotactic experiment of HCB316 with the response of cells to the stimulus of fructose $(1 \mathrm{mM}, 10 \mathrm{mM}, 50 \mathrm{mM})$ were different.

The $\mathrm{CW}$ bias shown in Fig. 3A was the same with the result in Fig. 2 under the stimulus of fructose $1 \mathrm{mM}$, while the $\mathrm{CW}$ bias shown in Fig. 3B under the stimulus of fructose $10 \mathrm{mM}$ was stable above 0 before and after the addition of the stimulus, and gradually increased after the removal of the stimulus. The CW bias 
shown in Fig. 3C under the stimulus of fructose $50 \mathrm{mM}$ was stable above 0 before the addition of the stimulus, and gradually decreased to 0 after the stimulus, then recovered to the pre-stimulus level.

All of the results above showed the cells of E. coli deleted all chemoreceptors cannot respond to the stimulus of fructose, along with the cells of E. coli deleted chemoreceptors except for Trg can response to the stimulus of fructose in high concentration. Thus, E. coli needs chemoreceptors to sense fructose.

Effect of fructose on the motility of E. coli

The strain JY26 transformed with the plasmid pKAF131 were used in the experiment. Figure 4A and Fig. 4B showed the speed: the average motor speeds of the wild-type strain (JY26) in CCW direction were $63.83 \pm 8.62 \mathrm{~Hz}, 54.18 \pm 12.38 \mathrm{~Hz}, 57.93 \pm 10.24 \mathrm{~Hz}, 55.11 \pm 10.27 \mathrm{~Hz}, 60.73 \pm 9.04 \mathrm{~Hz}, 61.98 \pm 7.84 \mathrm{~Hz}$, while the average motor speeds of the wild-type strain in CW direction were $55.75 \pm 8.84,52.68 \pm 11.16 \mathrm{~Hz}$, $54.2 \pm 9.66 \mathrm{~Hz}, 52.58 \pm 10.14 \mathrm{~Hz}, 57.97 \pm 8.53 \mathrm{~Hz}, 58.01 \pm 7.39 \mathrm{~Hz}$, under the concentrations of fructose from $0 \mathrm{mM}$ to $0.1 \mathrm{mM}, 1 \mathrm{mM}, 10 \mathrm{mM}, 20 \mathrm{mM}, 50 \mathrm{mM}$, respectively. The CCW motor speeds of JY26 in $0.1 \mathrm{mM}$ concentration of fructose decreased dramatically, which was reduced by $15.6 \%$ compared to the control in $0 \mathrm{mM}$ concentration of fructose. In contrast, the CW motor speeds of JY26 showed no distinct difference. Therefore, the fructose had an influence on the motor speed with the influence on CCW rotation was greater than on CW rotation. The CW biases of the motors of the wild-type strain JY26 were shown in Fig. 4C. Obviously, the CW bias of the motor increased with the addition of fructose. We also measured the motor speeds of the strains that were defective in chemotaxis, as shown in Fig. S1. The average motor speeds of the strain JY27 in CCW direction were $48.94 \pm 10.32 \mathrm{~Hz}, 49.75 \pm 12.91 \mathrm{~Hz}$, corresponding to $0 \mathrm{mM}$ and $50 \mathrm{mM}$ concentration of fructose. The average motor speeds of the strain HCB429 in CCW direction were $49.37 \pm 7.66 \mathrm{~Hz}, 47.46 \pm 6.27 \mathrm{~Hz}, 50.04 \pm 2.43 \mathrm{~Hz}$, corresponding to $0 \mathrm{mM}$, $1 \mathrm{mM}$ and $50 \mathrm{mM}$ concentration of fructose. Both of these results suggested that fructose has no effect on the motor speeds of the strains that were defective in chemotaxis.

Fructose promotes bacterial aggregation on surface by lowering the bacteria motor speed

The phenomenon that the bacteria accumulated on the surface when they swim near a surface, was clearly revealed by measuring the steady-state cell distribution of the cells swimming between two parallel surfaces, with cell density increased rapidly near the surface $(15,17)$. The reduction of motor speed would further help the aggregation near a surface. We found the motor speeds of wild-type strain reduced with the addition of fructose. To test whether the reduction of the motor speeds influenced the aggregation of the cells near a surface, we measured the steady-state cell distribution of bacteria swimming between two parallel surfaces in a depth of $150 \mu \mathrm{m}$. We compared the distributions for wildtype cells (JY26) in different concentrations of fructose $(0 \mathrm{mM}, 0.1 \mathrm{mM}, 1 \mathrm{mM}, 10 \mathrm{mM}, 20 \mathrm{mM}, 50 \mathrm{mM})$, finding that the cells with the addition of fructose accumulated more significantly, as shown in Fig. 5. To verify whether the fructose affects the steady-state cell distribution of the strains that were chemotactic defective, we measured the distributions for cells (JY27 and HCB429) in different concentrations of fructose $(0 \mathrm{mM}, 0.1 \mathrm{mM}, 1 \mathrm{mM}, 10 \mathrm{mM}, 20 \mathrm{mM}, 50 \mathrm{mM})$. The cell accumulation of the bacteria that were chemotactic defective showed no difference as shown in Fig. S2, which was distinct compared to wild- 
type cells. Therefore the fructose promotes the aggregation of the bacteria near a surface by lowering the motor speed of bacteria.

\section{Discussion}

In summary, we measured the chemotaxis response curve of wild-type cells and cells that were chemotactic defective to fructose in a wide range of concentrations from $0 \mathrm{mM}$ to $50 \mathrm{mM}$, finding that fructose is an attractant to $\mathrm{E}$. coli, with the wild-type cells showed stronger response to higher concentration of fructose, while cells lacking chemoreceptors and CheY cannot sense or respond to fructose. Previous work showed the chemoreceptor that sense sugars occupies only about $1 \%$ of the total chemoreceptors in wild-type cells, and the clustering of multiple types of receptors ensures the sensitivity and range response of E. coli to attractant $(2,20,22)$, which accounts for the results that the wild-type cells can sense fructose in a wide range of concentrations as well as the overshoot phenomenon $(18,19)$ observed in $50 \mathrm{mM}$ concentration of fructose, along with the consequence that mutants lacking chemoreceptors cannot sense fructose. Since $\mathrm{CheY}$ is an important molecule in the chemotaxis pathway $(5,21)$, the mutant lacking CheY cannot perform chemotaxis with its motor rotates only in CCW direction, resulting in no response to fructose.

We also measured the motor speeds for wild-type cells and cells that were chemotactic defective in various concentrations of fructose, with the consequence that fructose affects the motor behavior of wild-type cells and reduces the CCW motor speeds significantly compared to CW motor speeds, contrast to that fructose cannot affect the motor speeds of cells defective in chemotaxis. The CW biases of wildtype cells increased with the addition of fructose. Cells of E. coli swim up gradients of chemical attractants in aquatic environment by modulating their flagellar motors rotation direction between CCW and $\mathrm{CW}$, which determines the cells run or tumble, previous study revealed the CCW rotation speeds are higher than the $\mathrm{CW}$ rotation speeds for the reason that higher speeds in CCW rotation favors the cells to sense spatial gradients, whereas CW rotation does not require high speeds (23). In an aquatic environment rich in nutrition, high speeds in CCW rotation are not required for the cells of E. coli to sense the spatial gradients. Thus the motor speeds of CCW rotation might decreased in medium abundant in fructose. Previous studies suggested the flagellar motor adapts to changes of the chemotaxis signaling pathway $(16,20)$. The flagellar motor of the mutants lacking chemoreceptors or chemotaxis response regulator, CheY-P, cannot adapt, thus the motor rotation speeds remain the same in different concentrations of fructose from zero to $50 \mathrm{mM}$. Moreover, it is plausible that the exploration for the cells to the spatial gradients in nutrient-rich environment, which could be quantified by $\mathrm{CW}$ bias of the motor rotation, is not necessary. Hence the $\mathrm{CW}$ biases of wild-type cells increased in medium abundant in fructose.

Recent studies identified the mechanosensing mechanisms for surface-sensing by bacteria (24-28). The rotating bacterial flagellar motor and flagellum were involved in the surface-sensing by bacteria. High viscosity in liquid medium or high load condition the flagellar motors experienced facilitate the cells swim near the surface, corresponding to that the motor rotation speeds in high load or high viscosity condition 
reduce. Our study shows that the wild-type cells accumulate more significantly near the surface in medium added with fructose, consistent with the result that fructose reduces the CCW motor speeds of wild-type cells. In contrast, the distributions of the cells that are chemotactic defective near the surface in different concentrations of fructose show no difference for the reason that the motor rotation speeds remain the same in different concentrations of fructose. Therefore, the fructose promotes bacterial aggregation on surface by lowering the bacteria motor speed.

\section{Conclusions}

In this study, we found fructose is an attractant to E. coli, with the wild-type cells showed stronger response to higher concentration of fructose, while cells lacking CheY or chemoreceptors cannot sense or respond to fructose. In addition, the CW biases of wild-type cells increased in medium abundant in fructose. We also found the motility of wild-type cells was reduced in the presence of fructose, which helped the aggregation of cells near the surface. However, the distributions of the cells that are chemotactic defective near the surface in different concentrations of fructose show no difference for the reason that the motor rotation speeds remain the same in different concentrations of fructose. Our results reveal fructose might play a critical role in the bacteria life between free-swimming and sedentary phase. Similar phenomena are expected to be found in the effect of other monosaccharides to Escherichia coli.

\section{Methods}

Strains and plasmids

Strains and plasmids are listed in Table 1. All strains used in this study were derived from E. coli K12 strain RP437: JY26 ( $\Delta$ fliC), JY27 ( $\Delta$ fliC $\Delta$ cheY), HCB429 ( $\Delta$ fliC $\Delta$ Tar-Tsr-Trg-Tap) and HCB316 ( $\Delta$ fliC $\Delta$ TarTsr-Tap), all of which were gifts from Junhua Yuan's lab. The plasmid pKAF131 expresses the sticky filament FliC ${ }^{\text {st }}$ constitutively (10). The plasmid pFD313 also expresses the sticky filament FliC ${ }^{\text {st }}$ constitutively. To measure the motility and chemotaxis response to fructose, JY26 transformed with pKAF131, JY27 transformed with pKAF131, HCB429 transformed with pKAF131 and HCB316 transformed with pFD313 were used.

Cell Culture

Cells were grown at $33^{\circ} \mathrm{C}$ to an OD600 between 0.45 and 0.50 in $10 \mathrm{ml} \mathrm{T-broth} \mathrm{supplemented} \mathrm{with} \mathrm{the}$ appropriate antibiotics. For bead assay, $1 \mathrm{ml}$ of the cells were collected by centrifugation ( $1 \mathrm{~min}$ at $5,000 \mathrm{~g}$ ), washed once in $1 \mathrm{ml}$ of motility medium (10 mM potassium phosphate / $1 \mathrm{mM}$ methionine /0.1 mM EDTA /10 mM lactic acid, pH 7.0) with D-(-)-fructose (PHR1001; Sigma), and resuspended in $1 \mathrm{ml}$ of this medium. For microfluidics assay, $1 \mathrm{ml}$ of the cells were collected by centrifugation ( $1 \mathrm{~min}$ at $5,000 \mathrm{~g}$ ), washed once in $1 \mathrm{ml}$ of motility medium, and resuspended in $1 \mathrm{ml}$ of this medium. The resuspension were used for experiments immediately or stored at $4^{\circ} \mathrm{C}$ for up to $2 \mathrm{~h}$. 
For the bead assay, cells were sheared by passing $1 \mathrm{ml}$ of the washed cell suspension 150 times between two syringes equipped with 23-guage needles to truncate flagella and connected by a 7-cm-long polyethylene tubing $(0.58 \mathrm{~mm}$ inside diameter), and condensed into $300 \mu \mathrm{l}$ of motility medium with different concentrations of D-(-)-fructose ( $0 \mathrm{mM}, 0.1 \mathrm{mM}, 1 \mathrm{mM}, 10 \mathrm{mM}, 20 \mathrm{mM}, 50 \mathrm{mM})$. 1.0-mmdiameter polystyrene latex beads were attached to the filament stubs. All experiments were performed at $23^{\circ} \mathrm{C}$. Rotation of the bead was monitored with a bright-field setup. Rotational velocity as a function of time was determined for each motor and smoothed with a 10-point running average. CW bias was calculated over a 30 -s interval every $1 \mathrm{~s}$, thus to a plot of CW bias versus time $(10,13)$.

For the microfluidics, to perform long-time measurements of the chemotaxis, a flow chamber was constructed by using a rectangle-shape double-sided sticky tape (about $100 \mu \mathrm{m}$ thick) as a spacer between a glass coverslip coating poly-L-lysine (0.1\%, P8920; Sigma) and a glass slide with two 0.75$\mathrm{mm}$-diameter holes. The periphery of the chamber was sealed with Apiezon vacuum grease additionally. The flow chamber was kept under the constant flow of fresh motility medium with different concentrations of D-(-)-fructose $(0 \mathrm{mM}, 0.1 \mathrm{mM}, 1 \mathrm{mM}, 10 \mathrm{mM}, 20 \mathrm{mM}, 50 \mathrm{mM})$ at the rate of $250 \mu \mathrm{l} / \mathrm{min}$ using a syringe pump (14). The cells were added and incubated for $3 \mathrm{~min}$. Then, a $0.13 \%(\mathrm{w} / \mathrm{v})$ solution of 1.0- $\mu$ m-diameter polystyrene beads (2.6\%, no.07310-15; Polysciences) was added and incubated for 3 min until enough beads were attached to the sheared flagellar stubs. Finally, the unstuck cells and beads were rinsed with the flow of motility medium. The rotation of the beads was monitored using a Nikon Ti-E phase-contrast microscope with a $40 \times$ objective and recorded with a scientific CMOS camera (DCC3260M) at 500 frames per second. All experiments were carried out at $23^{\circ} \mathrm{C}$.

Measurement Of Cell Distribution Near Surface

$0.5 \mathrm{~mL}$ of cell cultures were pelleted by centrifuging at $1200 \times \mathrm{g}$ for $6 \mathrm{~min}$ and resuspended in $1 \mathrm{~mL}$ of $0.005 \%$ PVP-40 in motility medium mixed with fructose under various concentrations (to prevent adsorption of cells to the bottom glass) gently. And then, $0.4 \mathrm{ml}$ of the washed cell solution was mixed with $0.5 \mathrm{~mL}$ Percoll (the final concentrations of fructose were $0,0.1 \mathrm{mM}, 1 \mathrm{mM}, 10 \mathrm{mM}, 20 \mathrm{mM}, 50 \mathrm{mM}$ ) to match the cell buoyant densities and medium. A chamber was constructed by using a square-shape double-sided sticky tape with two pieces of double-sided tape as a spacer between a glass slide and the coverslip, in which the sample thickness is $₫ 150 \mu \mathrm{m}$. $100 \mu \mathrm{L}$ mixed cells were added to the chamber, which was then sealed with the Apiezon vacuum grease. The sample was allowed standing for $5 \mathrm{~min}$, which ensures the cell distribution reaches a steady state. A phase-contrast Nikon Ti2-E inverted microscope with a $40 \times$ objective (numerical aperture: 0.75 ; depth of field: $6.0 \mu \mathrm{m}$ ) and a scientific CMOS camera (DCC3260M) were used to image the population of swimming cells (15). Images were recorded starting at $3 \mu \mathrm{m}$ above the bottom glass surface and at steps of $8.3 \mu \mathrm{m}$ until the position within $3 \mu \mathrm{m}$ of the upper glass surface was reached. At each position, two images were recorded separated by $1 \mathrm{~s}$, with an exposure time of $0.1 \mathrm{~s}$. The non-motile cells were identified by comparison of the two images and discarded from the counting of cell numbers. The measurements were repeated with other samples 8 times for JY26 in $0 \mathrm{mM}$ concentration of fructose, and 8, 8, 8, 9, 8 times, respectively for JY26 with fructose under various concentrations $(0.1 \mathrm{mM}, 1 \mathrm{mM}, 10 \mathrm{mM}, 20 \mathrm{mM}, 50 \mathrm{mM})$. 


\section{Abbreviations}

E. coli

Escherichia coli;

CW

Clockwise;

CCW

Counterclockwise;

CheY-P

Phosphorylated CheY

\section{Declarations}

Ethics approval and consent to participate

Not applicable

Consent for publication

Informed consent for publication was obtained from all authors

\section{Availability of data and material}

We declared that materials described in the manuscript, including all relevant raw data, will be freely available to any scientist wishing to use them for non-commercial purposes, without breaching participant confidentiality.

\section{Competing interests}

The authors declare that they have no competing interests.

\section{Funding}

This work was supported by the National Natural Science Foundation of China Grants 11804072, the Fundamental Research Funds for the Central Universities (PA2018GDQT0015), and Anhui Natural Science Foundation Grant 1808085QC64.

\section{Authors' contributions}

FW and JL planned the work; FL and FW performed the measurements; FL and FW wrote the paper. FL and FW contributed equally to this work. All authors read and approved the final manuscript.

\section{Acknowledgements}

We thank Junhua Yuan for the strains as gifts. 


\section{References}

1. Berg, H. C. (2003). The rotary motor of bacterial flagella. Annual review of biochemistry, 72(1), 19-54.

2. Bray, D., Levin, M. D., \& Morton-Firth, C. J. (1998). Receptor clustering as a cellular mechanism to control sensitivity. Nature, 393(6680), 85.

3. Cluzel, P., Surette, M., \& Leibler, S. (2000). An ultrasensitive bacterial motor revealed by monitoring signaling proteins in single cells. Science, 287(5458), 1652-1655.

4. Turner, L., Ryu, W. S., \& Berg, H. C. (2000). Real-time imaging of fluorescent flagellar filaments. Journal of bacteriology, 182(10), 2793-2801.

5. Sourjik, V., \& Berg, H. C. (2002). Binding of the Escherichia coli response regulator CheY to its target measured in vivo by fluorescence resonance energy transfer. Proceedings of the National Academy of Sciences, 99(20), 12669-12674.

6. Alon, U., Surette, M. G., Barkai, N., \& Leibler, S. (1999). Robustness in bacterial chemotaxis. Nature, 397(6715), 168.

7. Gabel, C. V., \& Berg, H. C. (2003). The speed of the flagellar rotary motor of Escherichia coli varies linearly with protonmotive force. Proceedings of the National Academy of Sciences, 100(15), 87488751.

8. Kojima, S., \& Blair, D. F. (2004). Solubilization and purification of the MotA/MotB complex of Escherichia coli. Biochemistry, 43(1), 26-34.

9. Minamino, T., \& Imada, K. (2015). The bacterial flagellar motor and its structural diversity. Trends in microbiology, 23(5), 267-274.

10. Wang, F., Shi, H., He, R., Wang, R., Zhang, R., \& Yuan, J. (2017). Non-equilibrium effect in the allosteric regulation of the bacterial flagellar switch. Nature Physics, 13(7), 710.

11. Adler, J., Hazelbauer, G. L., \& Dahl, M. M. (1973). Chemotaxis toward sugars in Escherichia coli. Journal of Bacteriology, 115(3), 824-847.

12. Berg, H. C. (1975). Chemotaxis in bacteria. Annual review of biophysics and bioengineering, 4(1), 119-136.

13. Wang, F., Yuan, J., \& Berg, H. C. (2014). Switching dynamics of the bacterial flagellar motor near zero load. Proceedings of the National Academy of Sciences, 111(44), 15752-15755.

14. Zhang, C., He, R., Zhang, R., \& Yuan, J. (2018). Motor adaptive remodeling speeds up bacterial chemotactic adaptation. Biophysical journal, 114(5), 1225-1231.

15. Wang, R., Wang, F., He, R., Zhang, R., \& Yuan, J. (2018). The second messenger c-di-GMP adjusts motility and promotes surface aggregation of bacteria. Biophysical journal, 115(11), 2242-2249.

16. Yuan, J., Branch, R. W., Hosu, B. G., \& Berg, H. C. (2012). Adaptation at the output of the chemotaxis signalling pathway. Nature, 484(7393), 233.

17. Li, G., \& Tang, J. X. (2009). Accumulation of microswimmers near a surface mediated by collision and rotational Brownian motion. Physical review letters, 103(7), 078101. 
18. Berg, H. C., \& Tedesco, P. M. (1975). Transient response to chemotactic stimuli in Escherichia coli. Proceedings of the National Academy of Sciences, 72(8), 3235-3239.

19. Min, T. L., Mears, P. J., Golding, I., \& Chemla, Y. R. (2012). Chemotactic adaptation kinetics of individual Escherichia coli cells. Proceedings of the National Academy of Sciences, 109(25), 98699874.

20. Yuan, J., \& Berg, H. C. (2013). Ultrasensitivity of an adaptive bacterial motor. Journal of molecular biology, 425(10), 1760-1764.

21. Sourjik, V., \& Berg, H. C. (2002). Receptor sensitivity in bacterial chemotaxis. Proceedings of the National Academy of Sciences, 99(1), 123-127.

22. Hazelbauer, G. L., Falke, J. J., \& Parkinson, J. S. (2008). Bacterial chemoreceptors: high-performance signaling in networked arrays. Trends in biochemical sciences, 33(1), 9-19.

23. Yuan, J., Fahrner, K. A., Turner, L., \& Berg, H. C. (2010). Asymmetry in the clockwise and counterclockwise rotation of the bacterial flagellar motor. Proceedings of the National Academy of Sciences, 107(29), 12846-12849.

24. Hughes, K. T., \& Berg, H. C. (2017). The bacterium has landed. Science, 358(6362), 446-447.

25. Ellison, C. K., Kan, J., Dillard, R. S., Kysela, D. T., Ducret, A., Berne, C., ... \& Dalia, A. B. (2017). Obstruction of pilus retraction stimulates bacterial surface sensing. Science, 358(6362), 535-538.

26. Hug, I., Deshpande, S., Sprecher, K. S., Pfohl, T., \& Jenal, U. (2017). Second messenger-mediated tactile response by a bacterial rotary motor. Science, 358(6362), 531-534.

27. Luo, Y., Zhao, K., Baker, A. E., Kuchma, S. L., Coggan, K. A., Wolfgang, M. C., ... \& O’Toole, G. A. (2015). A hierarchical cascade of second messengers regulates Pseudomonas aeruginosa surface behaviors. MBio, 6(1), e02456-14.

28. Persat, A., Inclan, Y. F., Engel, J. N., Stone, H. A., \& Gitai, Z. (2015). Type IV pili mechanochemically regulate virulence factors in Pseudomonas aeruginosa. Proceedings of the National Academy of Sciences, 112(24), 7563-7568.

\section{Supplementary Figure Captions}

FIGURE S1 The CCW rotation speeds of the strain JY27, HCB429 and HCB316 in medium with fructose.

(A) The CCW rotation speeds of the strain JY27 under $0 \mathrm{mM}$ and $50 \mathrm{mM}$ concentration of fructose. The numbers of the motors measured at each point were 12 and 11, respectively. (B) The CCW rotation speeds of the strain HCB429 under $0 \mathrm{mM}, 1 \mathrm{mM}$ and $50 \mathrm{mM}$ concentration of fructose. The numbers of the motors measured at each point were 29, 20 and 7, respectively. (C) The CCW rotation speeds of the strain HCB316 under $0 \mathrm{mM}, 1 \mathrm{mM}, 10 \mathrm{mM}$ and $50 \mathrm{mM}$ concentration of fructose. The numbers of the motors measured at each point were $36,8,4$ and 24 , respectively. The bars and errors are means and std.

FIGURE S2 Density distribution of bacteria swimming near surfaces for the strain JY27 and HCB429. 
Density distribution of bacteria swimming between two parallel glass surfaces in a depth of $150 \mu \mathrm{m}$. The subfigure $A$ and $B$ were corresponded to the strain JY27 and HCB429. (A) The numbers of measurement repeats under different concentrations $(0.1 \mathrm{mM}, 1 \mathrm{mM}, 10 \mathrm{mM}, 20 \mathrm{mM}, 50 \mathrm{mM})$ of fructose were $8,8,8,8,8$ and 8 , respectively. (B) The numbers of measurement repeats under different concentrations $(0.1 \mathrm{mM}$, $1 \mathrm{mM}, 10 \mathrm{mM}, 20 \mathrm{mM}, 50 \mathrm{mM}$ ) of fructose were $8,8,8,7,8$ and 8 , respectively.

\section{Table}

TABLE 1. Strains and Plasmids used in this study

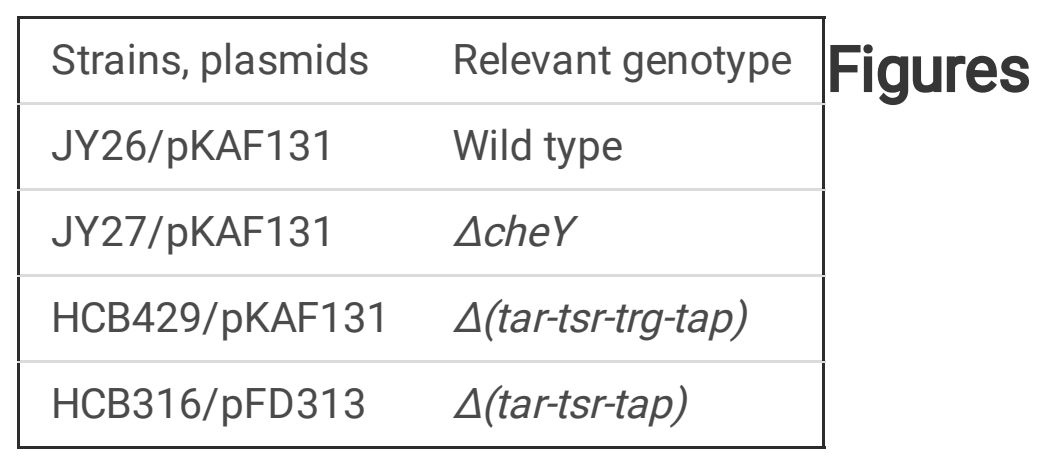




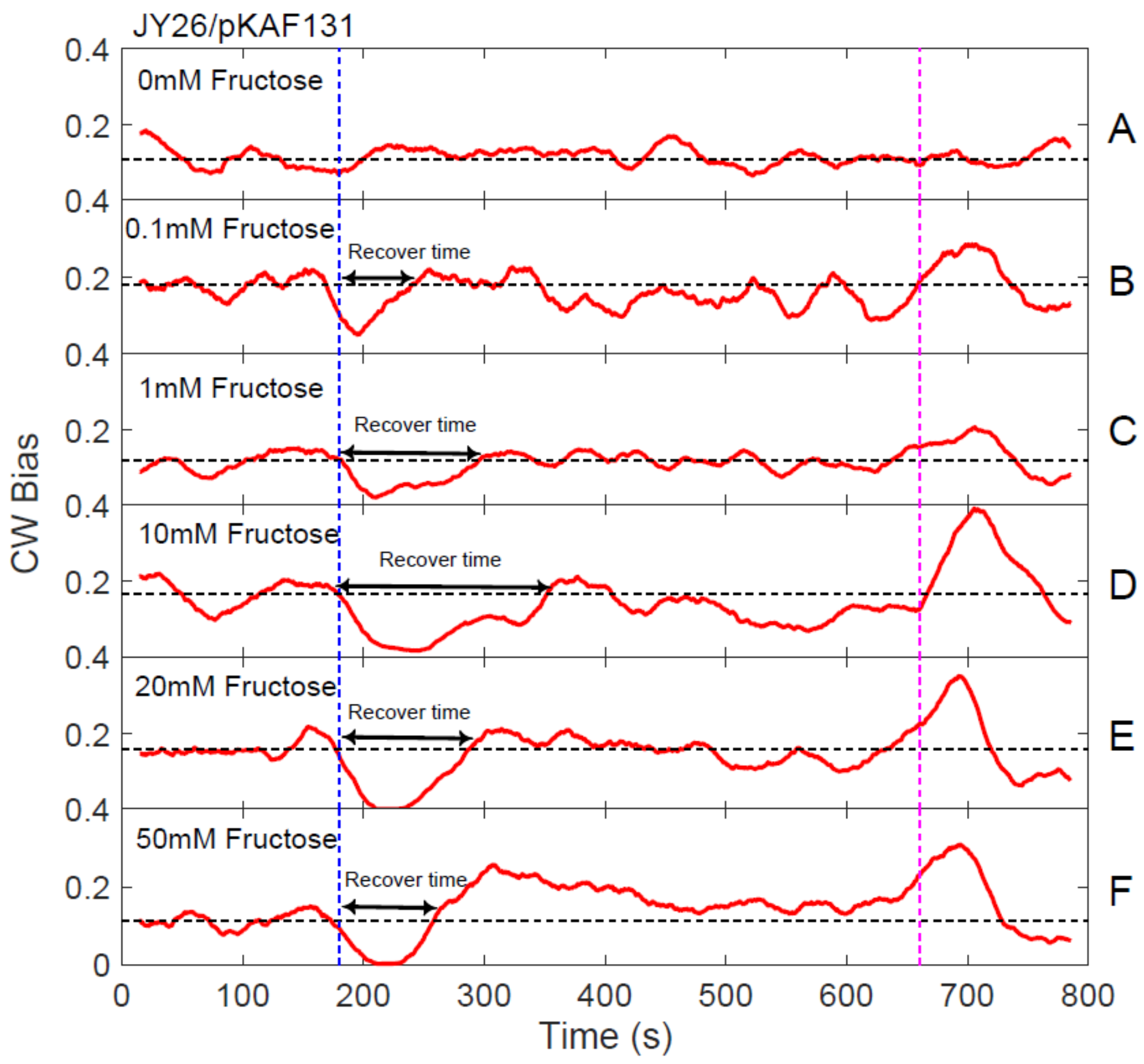

Figure 1

Motor response of the strain JY26 to stepwise addition and removal of fructose. The fructose was added (blue) and removed (purple) at the times indicated by the vertical dashed line. The dashed black line represents the average of the $C W$ bias from 0 to $3 \mathrm{~min}$. The subfigure $A, B, C, D, E$ and $F$ were corresponded to $0 \mathrm{mM}, 0.1 \mathrm{mM}, 1 \mathrm{mM}, 10 \mathrm{mM}, 20 \mathrm{mM}$ and $50 \mathrm{mM}$ concentration of fructose. The recovery time corresponding to the fructose of different concentrations $(0.1 \mathrm{mM}, 1 \mathrm{mM}, 10 \mathrm{mM}, 20 \mathrm{mM}, 50 \mathrm{mM})$ were $59 \pm 10.160 \mathrm{~s}, 113 \pm 9.068 \mathrm{~s}, 171 \pm 13.306 \mathrm{~s}, 105 \pm 11.082 \mathrm{~s}$ and $77 \pm 5.808 \mathrm{~s}$, respectively (mean $\pm \mathrm{std}$ ). The numbers of the motors measured at each section were $9,5,12,8,11$ and 11 , respectively. 

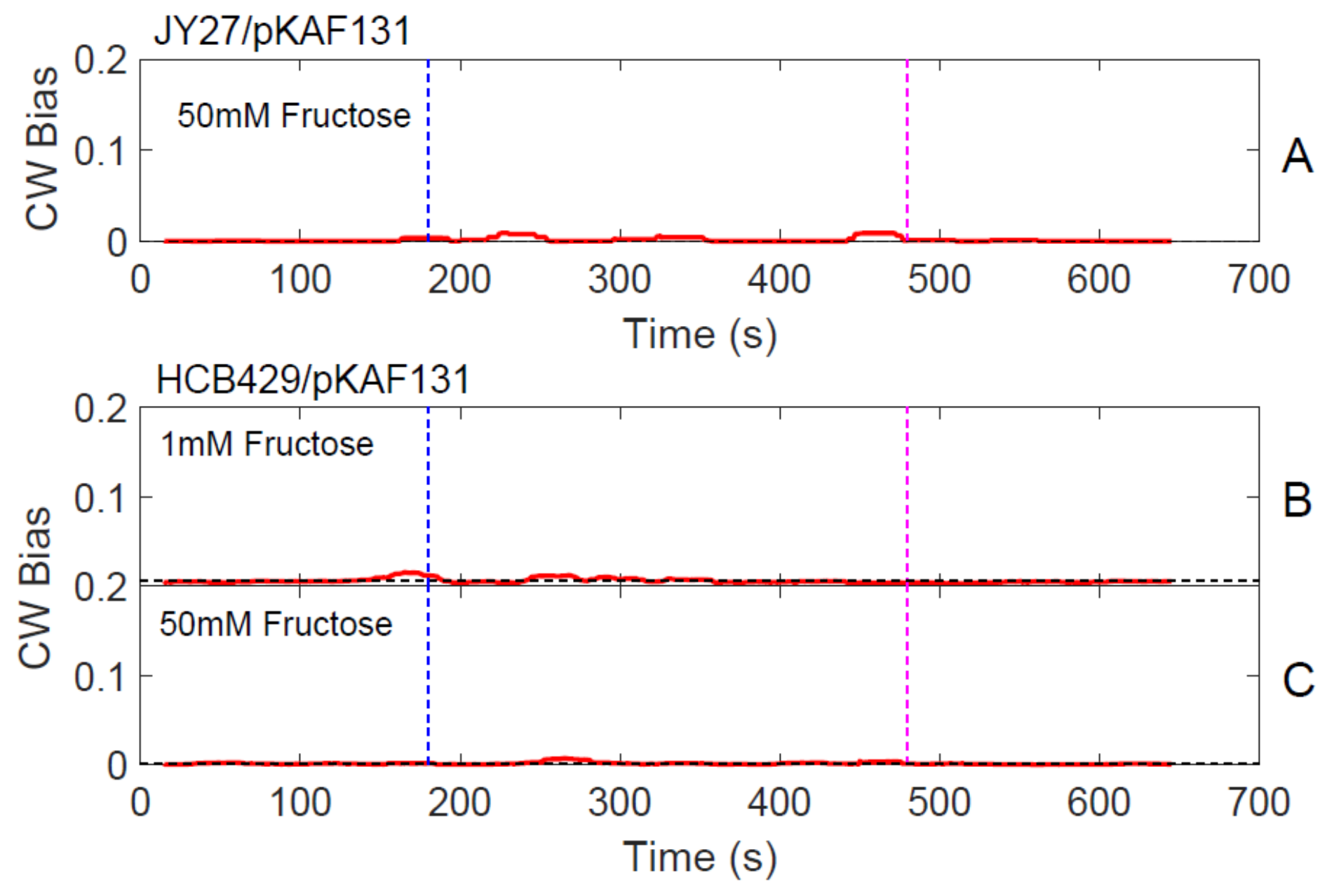

Figure 2

Motor response of the strain JY27 and HCB429 to stepwise addition and removal of fructose. (A) Motor response of the strain JY27 to stepwise addition and removal of fructose. The number of the motors measured at this section was 5. (B,C) Motor response of the strain HCB429 to stepwise addition and removal of fructose. The subfigure $B$ and $C$ were corresponded to $1 \mathrm{mM}$ and $50 \mathrm{mM}$ concentration of fructose. The numbers of the motors measured at each section were 15 and 9, respectively. The fructose was added (blue) and removed (purple) at the times indicated by the vertical dashed line. The dashed black line represents the average of the $\mathrm{CW}$ bias from 0 to $3 \mathrm{~min}$. 


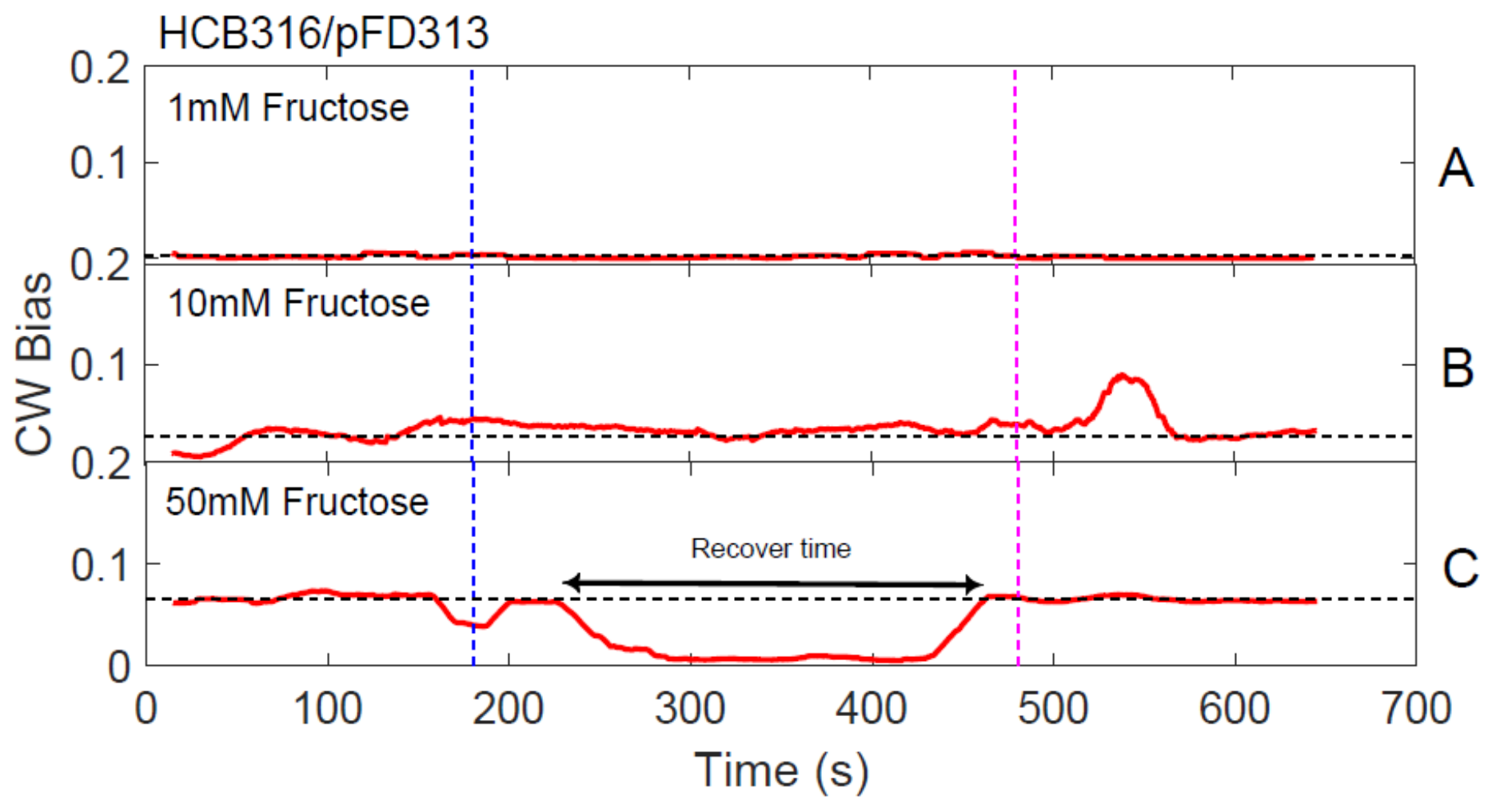

Figure 3

Motor response of the strain HCB316 to stepwise addition and removal of fructose. The fructose was added (blue) and removed (purple) at the times indicated by the vertical dashed line. The dashed black line represents the average of the $C W$ bias from 0 to $3 \mathrm{~min}$. The subfigure $A, B$ and $C$ were corresponded to $1 \mathrm{mM}, 10 \mathrm{mM}$ and $50 \mathrm{mM}$ concentration of fructose. The recovery time corresponding to $50 \mathrm{mM}$ concentration of fructose was $233 \pm 17.094 \mathrm{~s}$ (mean $\pm \mathrm{std}$ ). The numbers of the motors measured at each section were 6,4 and 17 , respectively. 

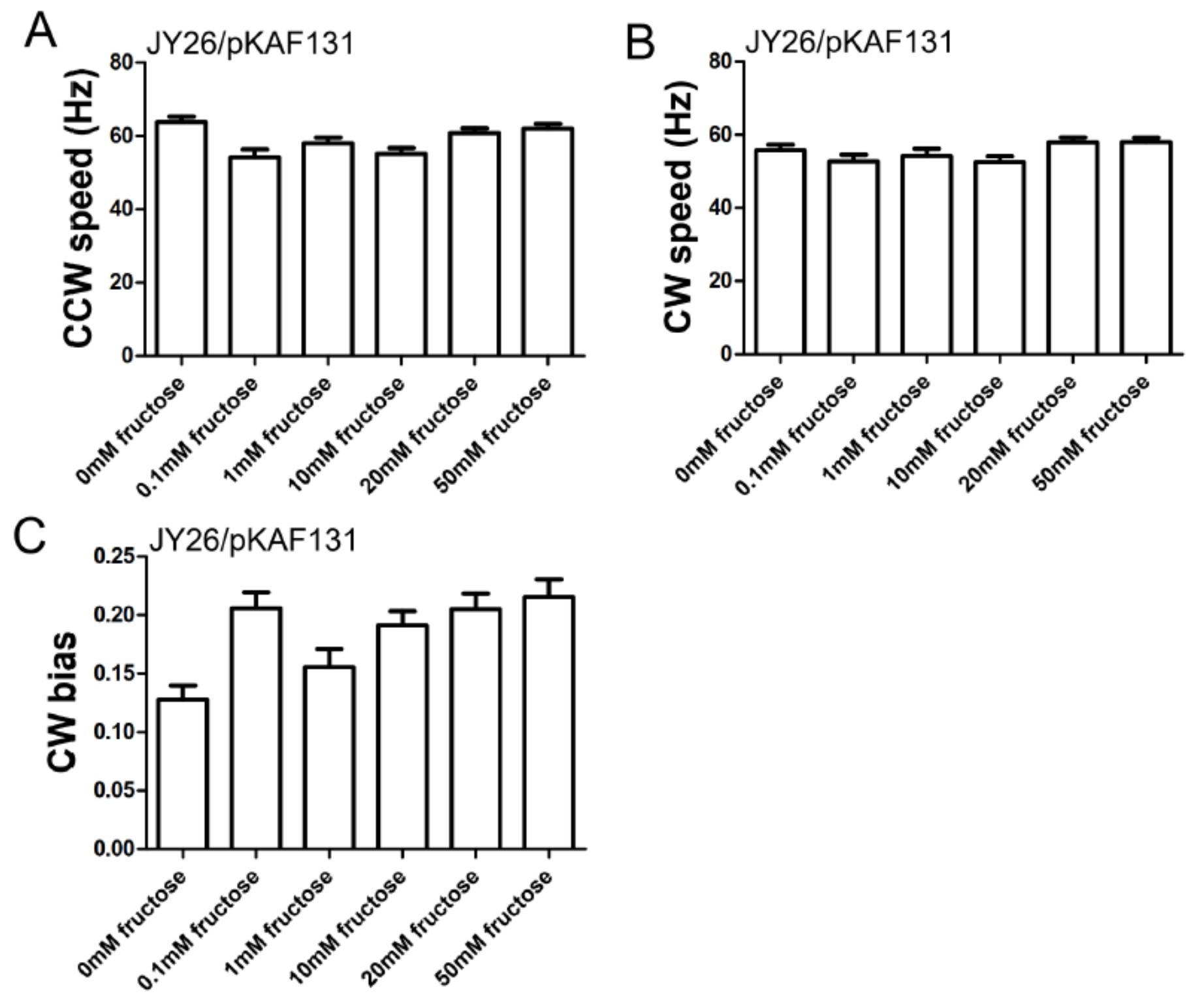

Figure 4

The rotation speeds and CW bias of the strain JY26 under various concentrations of fructose. (A) The CCW rotation speeds of the wild-type strain JY26 under various concentrations $(0 \mathrm{mM}, 0.1 \mathrm{mM}, 1 \mathrm{mM}$, $10 \mathrm{mM}, 20 \mathrm{mM}, 50 \mathrm{mM}$ ) of fructose. (B) The CW rotation speeds of the wild-type strain JY26 under various concentrations $(0 \mathrm{mM}, 0.1 \mathrm{mM}, 1 \mathrm{mM}, 10 \mathrm{mM}, 20 \mathrm{mM}, 50 \mathrm{mM})$ of fructose. (C) The CW bias of the wild-type strain JY26 under various concentrations $(0 \mathrm{mM}, 0.1 \mathrm{mM}, 1 \mathrm{mM}, 10 \mathrm{mM}, 20 \mathrm{mM}, 50 \mathrm{mM})$ of fructose. The numbers of the motors measured at each point were $33,35,39,43,43$ and 36 , respectively. The bars and errors are means and std. 


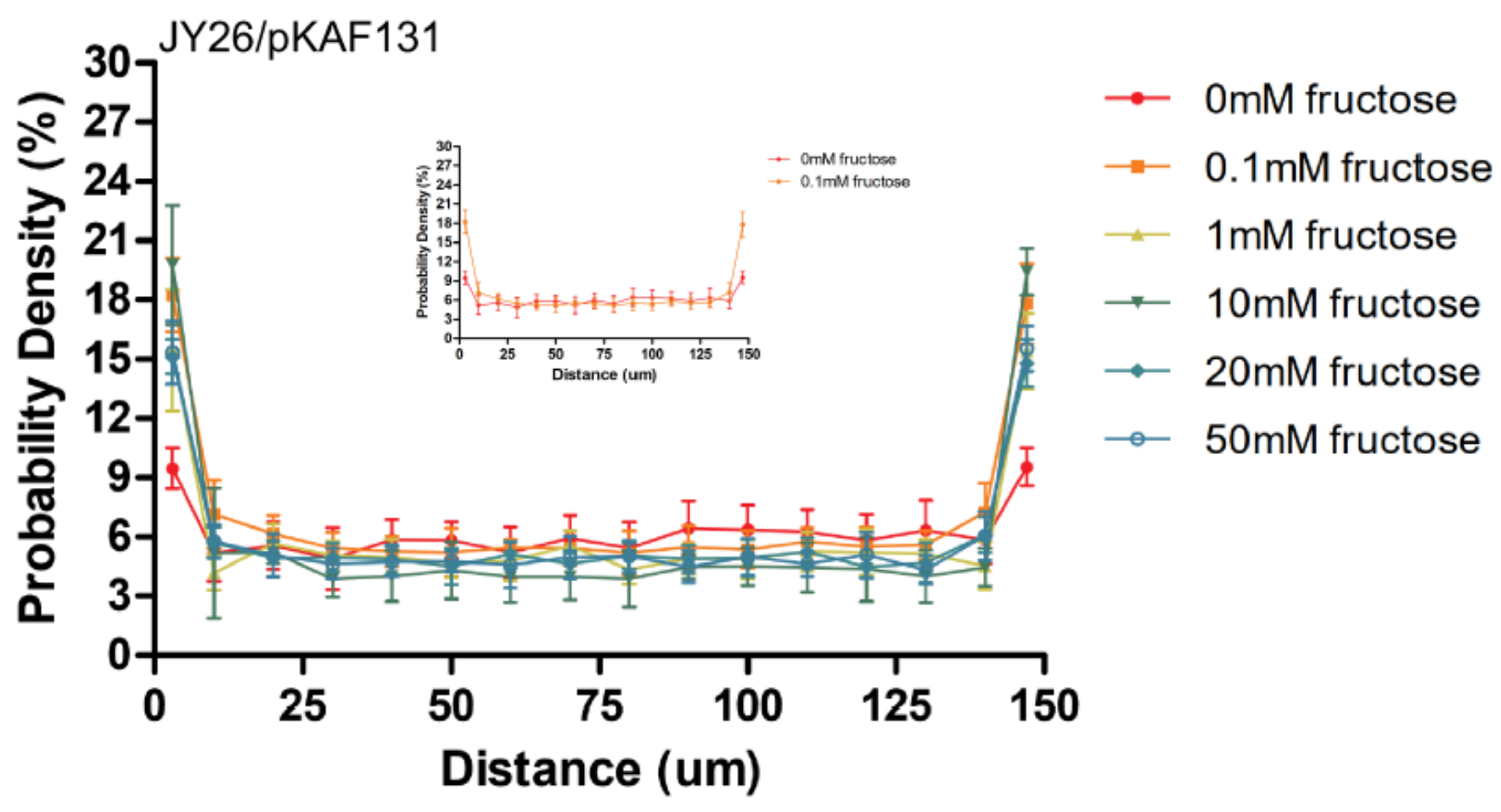

Figure 5

Density distribution of bacteria swimming near surfaces for the strain JY26. Density distribution of bacteria swimming between two parallel glass surfaces in a depth of $150 \mu \mathrm{m}$ for wild-type strain JY26. The cells accumulated more significantly with the addition of fructose $(0.1 \mathrm{mM})$ compared to without addition of fructose (shown in inset). The numbers of measurement repeats corresponding to the fructose of different concentrations $(0 \mathrm{mM}, 0.1 \mathrm{mM}, 1 \mathrm{mM}, 10 \mathrm{mM}, 20 \mathrm{mM}, 50 \mathrm{mM})$ were $8,8,8,8,9$ and 8 , respectively. 